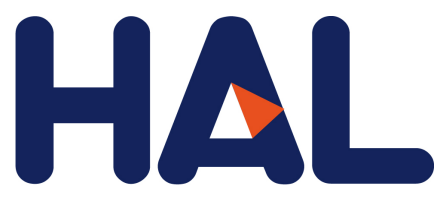

archives-ouvertes

\title{
The contribution of genomics in the medicine of tomorrow, clinical applications and issues
}

\author{
Bruno Laviolle, Patrice Denèfle, François Gueyffier
}

\section{To cite this version:}

Bruno Laviolle, Patrice Denèfle, François Gueyffier. The contribution of genomics in the medicine of tomorrow, clinical applications and issues. Thérapie, EDP Sciences, 2018, 74 (1), pp.9-15. 10.1016/j.therap.2018.11.012 . hal-02019324

HAL Id: hal-02019324

https://hal-univ-rennes1.archives-ouvertes.fr/hal-02019324

Submitted on 7 Mar 2019

HAL is a multi-disciplinary open access archive for the deposit and dissemination of scientific research documents, whether they are published or not. The documents may come from teaching and research institutions in France or abroad, or from public or private research centers.
L'archive ouverte pluridisciplinaire HAL, est destinée au dépôt et à la diffusion de documents scientifiques de niveau recherche, publiés ou non, émanant des établissements d'enseignement et de recherche français ou étrangers, des laboratoires publics ou privés. 


\section{THERAPIE}

\section{RUBRIQUE : GIENS WORKSHOPS 2018/TRANSLATIONAL}

\section{RESEARCH}

\section{EPUB AHEAD OF PRINT PUIS N 1 (jan fév) 2019}

The contribution of genomics in the medicine of tomorrow, clinical applications and issues*

Genomics in the medicine of tomorrow

Bruno Laviolle a,*, Patrice Denèfle ${ }^{b}$, François Gueyffier ${ }^{c}$, the participants of Giens XXXIV Round Table « Translational research », Élodie Béguéd, Pascal Bilbault ${ }^{\mathrm{e}}$, Hélène Espérou f, Florence Gaillard-Bigot g, Guillaume Grenet h, Jean-François Guérin i, Caroline Guillot j, Pierre-Henry Longeray k, Julia Morere ', Olivier Perche m, Lionel Perrier $^{\text {n }}$, Damien Sanlaville ${ }^{c, 0}$, Julien Thevenon ${ }^{p}$, Nathalie Varoqueaux ${ }^{q}$

a Univ Rennes, CHU Rennes, Service de Pharmacologie, Inserm, CIC 141435000 Rennes, France

${ }^{\mathrm{b}}$ Institut Roche, 92650 Boulogne Billancourt, France

c Université Lyon 1, faculté Laënnec, 69008 Lyon France

${ }^{d}$ Ligue nationale contre le cancer, 75013 Paris, France

e Lysarc, 69495 Pierre Bénite, France

${ }^{\mathrm{f}}$ Inserm, 75013 Paris, France

${ }^{\mathrm{g}}$ AP-HM, CHU Timone, 13005 Marseille, France

${ }^{\mathrm{h}}$ Hospices civils de Lyon, 69424 Lyon, France 


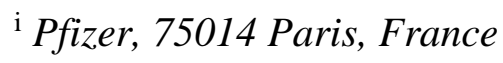

${ }^{\mathrm{j}}$ Fédération française des diabétiques, 75000 Paris, France

${ }^{\mathrm{k}}$ Ariis, 75015 Paris,, France

${ }^{1}$ CHLS, 69004 Lyon, France

${ }^{\mathrm{m}}$ Roche, 38242 Meylan, France

${ }^{\mathrm{n}}$ Univ. Lyon Claude Bernard, centre Léon Bérard, Gate L-ES UMR 5824, 69008 Lyon, France

o HCL, GHE génétique clinique, CHU de Lyon, neuroscience research center (CRNL), GENDEV team, CNRS UMR 5292, Inserm U 1028, UCBL 1, 69677 Bron, France

${ }^{\mathrm{p}}$ CHU de Grenoble, 38043 Grenoble, France

${ }^{\mathrm{q}}$ Astrazeneca, 92400 Courbevoie, France

Received 3 November 2018; accepted 13 November 2018

*Corresponding author. Service de pharmacologie clinique, hôpital de Pontchaillou, 2, rue Henri Le Guilloux, 35033, Rennes Cedex 9.

E-mail adress: bruno.laviolle@chu-rennes.fr_(B. Laviolle)

* Articles, analyses and proposals from Giens workshops are those of the authors and do not prejudice the proposition of their parent organization. 


\section{Summary}

Fifteen years after the completion of first human genome sequencing, the technique is almost a commodity but there is still little evidence of its usefulness as a diagnostic, prognostic or therapeutic tool. In France, the France genomics plan 2025 was launched in 2015 with the goal of integrating genomic tests into clinical practice and developing a National genomics network including industrial partnerships. Reflection on scientific applications and operational or societal issues is needed to make recommendations to help better associate Genomics and the medicine of tomorrow. In the perspective of personalized Evidence-based Medicine, studies with an appropriate methodological level to improve the definition of evidence should be promoted. The many operational challenges require the implementation of organisations and means to streamline the process of results reporting, and regulatory adaptations concerning the status of professions involved, the management of data generated, and the consent of patients. In parallel, genetic training for healthcare professionals and raising awareness on genetic tests for the public should be considered. The ethical stake should also be taken into account, especially on the participation of the patient in decisions concerning them and in the integrating the notion of uncertainty into the information given. The sociological effects on the experience and expectations of patients and the general population towards genomic medicine should also be evaluated to improve information, prevention and support for people. Finally, medicoeconomic studies must be conducted to inform policy-makers on the cost-effectiveness of complete genome sequencing for population health.

\footnotetext{
Abbreviations

ACLF: Association of French language cytogeneticits (Association des cytogénéticiens de langue française)
} 
Keywords: Diagnosis; Ethical issues; Personalized medicine; Prognosis; Therapeutics; Whole genome sequencingANPGM : National association of molecular genetics practitioners (Association nationale des praticiens de génétique moléculaire pour la génétique moléculaire)

ARS : Regional health agency (Agence régionale de santé)

AVIESAN: Alliance for life and health sciences (Alliance pour les sciences de la vie et de la santé)

CNIL: National commission for informatics and liberties (Commission nationale de l'informatique et des libertés)

CReFIX: Center for reference, innovation, expertise and transfert

DAC: data analysis collector

DCRR: differential cost-result ratio

DGOS: General direction of the offer care (Direction générale de l'offre de soins)

INCa: National institute of cancer (Institut national du cancer)

INSERM: French institute of health and medical research (Institut national de la santé et de la recherché médicale)

NGS: next generation sequency 


\section{Introduction}

In the early 1990s, the international scientific community undertook the largest collaborative project in history with the purpose of sequencing the complete human genome. In 2004 and at the price of several billion euros, the first whole human genome sequencing was made available to the international community [1]. In the years that followed, the tools of molecular biology have evolved significantly, in line with progress made in computer science and miniaturisation, so that today complete genome sequencing can be obtained in a few days and for less than 1000 $€[2-3]$. However, while the technique has become more easily accessible to the general population, there is little evidence of its usefulness as a diagnostic, therapeutic and prognostic tool. National programs have been initiated in recent years including the France genomics 2025 plan to evaluate the medical usefulness of whole genome sequencing for populations. It remains today that this major scientific advance of modern medicine raises multiple questions that are important to answer in the medical context (evidence of its utility for patients), as well as in a technical, sociological and economic context. The purpose of this round table was to reflect on the scientific applications and operational and societal challenges in order to make recommendations to better associate genomics and the medicine of tomorrow.

\section{The France genomics plan}

The France genomics 2025 plan was launched in 2015 with the goal of integrating genomic tests into clinical practice for validated indications and developing a National genomics network including industrial partnerships. The Plan is under the operational responsibility of the Alliance for life and health sciences (AVIESAN), which coordinates 13 work-groups in charge of driving coordination between partners, pilot research projects, industrial participation, the ethical, regulatory or medico-economic aspects, training and communication. The centre for reference, innovation, expertise and transfer (CReFIX) has also been set up to define, validate and implement the operational standards on sequencing platforms and on data analysis collector (DAC) and ensure the technological and computer research and developments required to deploy genomics. Several consortia of "bioinformatics pipelines" are being constructed with different private and public partners (French institute of bioinformatics) and a collaboration with Genomics England was signed in January 2018.

Four pilot projects are underway to test the functionality and coherence of the care course including the implementation of genome-wide sequencing on cohorts of targeted patient. The MULTIPLI program focuses on oncology including advanced soft-tissue sarcoma (MULTISARC project) and metastatic colo-rectal cancer (ACOMPLI project), the DEFIDIAG 
project focuses on patients with rare diseases, such as intellectual impairment, and the GLUCOGEN project includes patients with common diseases, such as diabetes. The last project is a general population study (POPGEN project) which aims to build a database of frequencies of genetic polymorphisms in the French population. This database will improve understanding of the involvement of genetic polymorphisms in pathologies. These clinical research projects are based on groups of professionals of various skills under the responsibility of universityhospitals recognised in their field. They are at different stages of progress, three of them with the first enrolments of participants (sick volunteers and healthy volunteers) planned for early 2019. Their development, as well as their future realisation, revealed various points of difficulty, the resolution of which is shared with the other working groups of the plan (information sheet and informed consent, circuit and quality of samples, characterisation of the results, etc.).

As part of the France genomics 2025 plan, France wanted to have high-throughput sequencing platforms as part of the care program. Twelve platforms are planned in the future. Two first pilot platforms, SeqOIA (Paris Ile de France Project) and AURAGEN (Auvergne Rhône Alpes project) were announced in July 2017 and should begin operations in 2019. The main goal of these platforms is to transfer the use of high-throughput sequencing (exome, transcriptome and whole genome) for the diagnosis of rare diseases and cancers. They must have an industrial production respecting the quality standards required for a medical diagnosis laboratory and allow access to the entire French population. According to the $6^{\text {th }}$ measure of the plan, evaluation and validation of new indications for accessing to genomic diagnosis is being implemented by the French national authority for health (HAS).

\section{Scientific and clinical applications}

\section{Findings}

Genomic data gives hope for the development of ever more personalized medicine [4]. However, access to this new information has its challenges: a high risk of false positive leading to a risk of optimism bias [5], which may contribute to the difficulty of scientific reproducibility [6]. Various risks related to genetics may also have a psycho-social impact for patients, induce overconsumption of additional examinations, or even lead to the contraindication of a drug yet shown to be effective elsewhere [7]. Thus, if personalized medicine and evidence-based medicine have been put back to back [8], an evidence-based approach is still needed to assess the level of evidence of associations between a genetic variant and a phenotype, to quantify the risk of these associations, and ultimately identify the clinical relevance of these findings in the 
patients' care-path or lifestyle. Evidence-based personalized medicine will allow the best use of the technological performances of high-throughput sequencing, both for i) prevention through early identification of actionable and targeted genetic predispositions[9] even highdimensional [10], ii) the etiological diagnosis of rare diseases by decreasing diagnostic wandering time, and the prognosis of certain cancers, but also iii) for therapy, by identifying factors that predict efficacy of targeted therapy and/or risk of adverse drug reactions. In this perspective, an evaluation of the level of evidence of pharmacogenetics was initiated by the National pharmacogenetics network [11]. Finally, there is still a lack of awareness of the needs and expectations of people, their representations, their experience of these techniques, psychosocial consequences and possible societal changes related to these technologies. If this sociological information is still little described, it would nevertheless help all actors in the chain: some to guide their research perspectives, others to guide patients and support them in this process (test, announcement and explanation, and follow-up given to the results of tests).

\section{Recommendations}

The prioritisation of studies on the implementation of genomics in clinical practice in a targeted way on groups of patients presenting a demand of care, an identified pathology, for which genomic knowledge may be of clinical interest, helps reduce the expected pitfalls of pangenomic sequencing in the general population, for people with no identified health claim, or non-medical, recreational or genealogical purposes. The place of genomic sequencing in the building of an "identity card of polymorphisms at risk of adverse drug reactions" also needs to be assessed [12].

In the perspective of a personalized evidence-based medicine, it is necessary to promote an appropriate level of methodological requirements and to improve the definition of the level of evidence, taking into account, for example, the imperative need for the replication of results. The indications of whole genome sequencing for diagnostic purposes must also be specified with regard to other existing diagnostic methods.

Regarding the prognostic significance of sequencing, including fortuitous, incidental and/or additional findings, the evaluation of the clinical relevance of this secondary data should consider the effects size of genetic polymorphisms, i.e. the quantitative importance of the increase in risk posed by - or associated with - the genetic variant and the accuracy of this measurement.

In the therapeutic context, the clinical utility of genetic polymorphisms predictive of the efficacy of a treatment should be assessed like for companion tests [13]. 
Concerning the prevention of adverse drug reactions, pharmacogenomic incidental knowledge should be incorporated into the care path, taking into account in the prescription of drugs its personalised risk/benefit balance, i.e. adjusted to the genotype. Ultimately, genomic information, relating to the risk of a disease or a modification of a drug effect, will contribute to the measurement of the net benefit of a treatment [14].

\section{Operational challenges}

\section{Technical issues}

Technological developments occur very quickly in Genomics. Currently the most robust technology and which allows industrialisation of sequencing is the so-called "short-read" technology. (sequencing of short DNA fragments in parallel) with a major player: the Illumina company which has the quasi-monopoly. However, so-called "long-read" technologies (sequencing of long DNA fragments) are developing rapidly and it is very likely that within 23 years, these technologies will compete with "short-reads" both in terms of performance and cost. Additionally, very high-throughput sequencing machines are very expensive (more than 1 million euros) and depreciation cannot be done over 2-3 years, which is a challenge for the economic model.

Several types of analyses will be performed on the platforms implemented with the France genomics plan (whole genome or exomes for rare diseases and exomes and transcriptomes for tumours). Harmonization of techniques is necessary to ensure that comparable results are rendered by both pilot platforms.

\section{Logistics Issues}

The France genomics 2025 plan insists on the possibility that each patient can access highthroughput sequencing platforms when he/she has a pathology corresponding to a medical indication defined within the plan. Thus, the pilot platforms must arrange a collection of samples throughout the whole country, including French overseas territories. The French ministry of health (General direction of the offer care [DGOS]) has recently proposed a geographic distribution based on pre-existing organizations in oncology and for rare diseases which is to be tested. Thus, depending on the place of residence, samples will be sent to the SeqOIA platform or the AURAGEN platform. As the SeqOIA and AURAGEN platforms are supported by private-sector GCSs, a pooled tender must be performed to homogenize the transport of samples under optimal safety and quality conditions, also taking into account the constraint that frozen tissue can be transported in the context of cancers. 


\section{Organisational issues}

The implementation of genome sequencing in current practice as a diagnostic/therapeutic tool also raises organisational issues related to the transdisciplinarity of this technique. The professions and skills concern geneticists, bio-informaticians, clinicians, pathologists, biostatisticians, methodologists and quality assurance specialists.

For cancers, the French national cancer institute (INCa) has been organising for several years the genomic diagnostic activity of tumours with the setting up of multidisciplinary molecular consultation meetings and diagnostics platforms accredited by INCa. For rare diseases, 23 subsidiaries of care were created with the second National rare diseases plan with rare disease reference centres, constituent centres and competence centres. Furthermore, at the biological level, two scientific societies: The National association of molecular genetics practitioners (ANPGM) for molecular genetics and the Association of French language cytogeneticists (ACLF) for cytogenetics, have set up organised and efficient diagnostic networks. The possibility to perform whole genome analysis to identify both nucleotide variants and changes in the number of copies will lead firstly to an overhaul of current diagnostic networks and secondly to a probable reorganisation of laboratories with a rapprochement of skills between molecular genetics and cytogenetics.

\section{The challenges of training/information}

Genetics knowledge evolves very rapidly and affects many specialties. Information obtained by whole genome analysis can sometimes identify genetic information that is not related to the indication that led to the prescription of the examination (incidental discoveries). It is therefore necessary to be able to properly inform patients, but also healthcare professionals. The particularity of genetic data may not be unique in medicine, but more important than elsewhere as they lead to a "probabilistic" interpretation and may have implications for other family members. It is therefore essential to educate physicians to help them providing adapted support for their patients on these concepts of uncertainty. More generally with the dissemination of genetic data of individuals, new professions will appear such as genetic advisors specialized in genomics. It will therefore be necessary to specify the status of these professions and implement appropriate training.

\section{Regulatory issues}

The two platforms set up by the France genomics plan are considered as new diagnostic laboratories and thus push the regional health project. The modalities for obtaining the 
authorisations of exercise issued by the Regional health agencies (ARS) and approvals to sign the reports will have to be specified.

The creation of a new laboratory requires the achievement of quality standard ISO 15189 , but the analyses performed on both platforms are considered innovative and therefore should not be subject to accreditation from the outset. However, this accreditation will be necessary as soon as these actions are reimbursed, which is one of the objectives of the plan. The regulatory aspects of the protection of data produced must also be specified. The management of genetic analysis data requires compliance with the French data protection authority (CNIL) and the general data protection regulation with the appointment of a data protection officer. Also, the automation required for industrial production requires strict computer traceability. Finally, the storage of data requires the structure to be licensed as a health data host.

\section{Challenges in big data management}

The platforms will generate a lot of genotypic and phenotypic data. Their optimal use in the interest of medical practice and the service given to the patient requires a connection of digital data, daily health data of life by computerised patient record, environmental data, and must be integrated in a health data hub

The approach of France genomics 2025 is to be compared to the construction of a National health data hub, the creation of institutes in artificial intelligence (3IA) and new projects in the field of artificial intelligence and health promoted by public and private bodies. This context of the aggregation of multi-scale data around the patient contributes to a profound transformation of the health ecosystem in France [15].

\section{Recommendations}

It now seems important to implement a multidisciplinary consultation meeting (RCP) upstream and downstream of high throughput sequencing integrated in the "genomic path" to take into account the genetic data in patients care. The implementation of these RCPs can be done in conjunction with those provided by the third National rare diseases plan using, in particular, common and/or interoperable computerized tools.

Means and organizations will need to be implemented to ensure adapted time of results. This involves optimising the prescription circuit with the use of a National e-prescription tool, optimising the transport of samples, promoting a qualification of tumour samples in centres with expert pathologists, optimising flow management on the platforms of the France genomics plan, developing the most automated analysis pipelines possible, and implement the data 
collector analyzer provided in the plan that will be able to process and exploit the high volume of data generated by matching it with the medical information.

The public health code will also have to be modified to separate the analytical and postanalytical phases to enable the France genomics plan platforms to ensure, if needed, only sequence production without the final medical report.

Incentives measures for the industry will have to be taken with the aim of optimising flows, deadlines for reporting results and pipeline development.

Training courses in genetics should be conducted for professionals, including general practitioners, medical students and patients with, for example, videos available online (INCa sites, rare diseases care networks, the France genomics plan, or French institute of health and medical research [Inserm]). In addition, advocacy actions and information campaigns on genetic tests should be carried out regarding the general public. The creation of a website ("mongenome.fr") bringing together the various sources of information available would aim to improve public information.

A regulatory definition of the status is required for new professions related to genome sequencing (bioinformaticians, genetic/genomic advisors...) to facilitate their integration into the genomic path and to recognise their place (hospitals, genetic laboratories, research structures...).

The regulatory framework for the management of data generated and access to this data must be defined to facilitate the integration of genomics into the broader context of health data exploitation (health data hub) and the interoperability of databases. These regulatory changes should specifically include a reflection on the evolution of genetic consent forms and the drafting of a charter for the use of data produced for research purposes.

\section{Ethical issues}

\section{Finding}

The implementing of genomics in medical practice will be accompanied by an evolution of the practices with the responsibility of the patient and the development of patient autonomy, and amplify the concept of shared medical decision. Various challenges can be highlighted. The question of the time availability of samples due to rapidly changing knowledge and technical possibilities enable us to re-analyse samples beyond the initial consent given by patients.

The question arises of the psychological follow-up of patients from the time a diagnosis is made: patients may feel abandoned to their fate, and particularly as this diagnosis may be associated with a potentially negative prognosis and with no therapeutic solution. Whole 
genome sequencing can indeed reveal deleterious information by means of its negative, anxiogenic prognosis with, for example, the discovery of a disease not known in the family. It may also reveal information useful for the therapeutic management and/or prevention, including specificities in drugs metabolism, or more rarely on drugs targets. The results of whole genome sequencing can also provide genetic information not requested by the patient. Should everything be researched and discussed? Is informing a patient of a secondary discovery ethical in itself? Information of the patient may be acceptable if it is appropriate, respectful of his/her interests, allows patient participation in decision making, and especially that the consent for the communication of results is obtained before the test and details the type of information that the patient will accept.

Other situations are also to be considered. Foetal DNA research, for example, allows the sequencing of the complete foetal genome and potentially exposes to a risk of eugenic drift. In response to these questions, and reinforcing them, the National ethics committee recently proposed a lifting of current regulatory restrictions [16].

Another important issue is the status of the genome. Does the subject own his/her own genome? Should we help protect them from the possibility of access by third parties, with malicious intent? The question arises particularly with regard to insurers who may be interested in genetic information, which could be the basis of insurance surcharges or exclusions. The donation of cells of the human body, especially gametes, currently subjected to the strict rule of anonymity, poses similar questions: it is no longer possible to guarantee to a donor that in any case the "recipient(s)" will be unable to discover his/her identity, through sequencing, the practice of which is becoming routine.

\section{Recommendations}

The discovery of incidental abnormalities should be anticipated, the patient must be well informed, with a systematic proposal to actively participate in decisions concerning him/her according to his/her expectations and by integrating the notion of uncertainty into the information delivered. Therapeutic stalemate situations must be prevented by targeting sequencing and its interpretation on actionable abnormalities. At the time of consent, the health care professional must seek to specify the willingness of the patient, a priori and in general, to access different types of information, opening on a consent adjusted to the different eventualities. Information given to the patient will follow the legislation, the recommendations of the French "Agence de la biomedicine", and the patient's desire. 
The notion of consent must be re-assessed with the search for the establishment of a dynamic consent to allow a possible re-use of the patient's genetic data after sampling (possibly with specific information).

The establishment of an observatory to improve knowledge on the sociological effects of genomics would also be interesting to understand the experiences and expectations of patients and the general population with regard to genomics and conducting sociological studies to identify ways to improve information, prevention (targeted and adapted) and supporting people. This observatory would also alert the ethics committee of potential changes or even shifts in collective representations and/or in people's practices in the face of genomics.

\section{Financial sustainability/economic model}

\section{Finding}

The advent of a new paradigm induced by the massive deployment of high- high-throughput sequencing raises economic and organisational issues. The evaluation of the production cost of genome sequences shows a notable change in the production costs of a gene panel targeted by next-generation sequencing (NGS) according to indications, enrichment techniques, retained sequencing, or the number of patients per run. In France, for example, the cost per patient (from the receipt of samples to the return of results to prescribers) varies from one to three depending on the laboratories [17]. What about the cost of genome sequencing? One can assume that production costs will largely depend on the organisational model chosen and its ability to integrate multiple technical constraints (prescription portals, automated extraction systems, production platform, IT infrastructure, data analysis, rendering of results, interoperability with patient records, etc.).

The medico-economic assessment of the genome-wide sequencing strategy is essential to inform policy makers on the cost-effectiveness (or not) of one or more innovative health strategies compared to the reference strategy(s). These assessments are planned in the pilot projects of the France genomics 2025 plan. This approach has well-known benefits such as the absence (most often) of selection bias. In contrast, the time horizon of the economic evaluation is usually limited to the follow-up period of the trial and differential cost-result ratio (DCRR) is not always expressed in cost per year of life gained in good health. These can also emanate from modelling. The review of the literature published by Schwarze et al. on genome sequencing reports a very limited number $(\mathrm{N}=8)$ of publications including a complete medicoeconomic assessment (i.e. that integrates economic considerations and clinical efficacy) [18]. Furthermore, the heterogeneity of the efficacy criteria does not favour comparisons between 
studies. Only one of them expresses the DCRR in cost per year of life gained in good health [19].

\section{Recommendations}

Robust organisational evaluations of this health strategy will need to be implemented as well as the use of Industrial engineering and automation tools. These models take into account the functioning of the systems: operational analysis (identification through petri networks of blocking points, lifting of the locks), risk analysis (identification of risks of non-feasibility, proposition of solutions in degraded mode to reduce associated losses, loss of chance for patients, selection of an inefficient production process, for example), structural analysis (identification of potential failures in the modelled pathway). The flows (information flows and physical flows) modelling can then be implemented by means of discrete events simulation integrating the heterogeneity of patient characteristics and of their disease [20].

They can also be coupled with economic assessment to select the only efficient production processes [21].

Similarly, the conduct of medico-economic evaluations in accordance with the recommendations of the HAS [22] will be essential for the France genomics plan to effectively meet its challenges. Use of the datamart of inter-regime consumption chained with the database of the Information system medicalisation program within the national health data system should also be encouraged in relation with the health data hub [23].

\section{Conclusion}

Genomics has evolved significantly in recent years and is a major challenge for the medicine of tomorrow. However, before its broad use in clinical practice, it is important to carry out careful evaluation of its interest in terms of diagnosis, therapeutic and prognosis value. Beyond the sole benefit of comprehensive genome-wide sequencing for population health, many organisational, ethical or economic questions must be addressed by the scientific community and civil society to take into account the difficulties and challenges that arise from its largescale implementation.

\section{Disclosure of interest}

Authors have no competing interest to declare 


\section{References}

[1] Lindor NM, Thibodeau SN, Burke W. Whole-genome sequencing in healthy people. Mayo Clin Proc 2017;92:159-72. doi: 10.1016/j.mayocp.2016.10.019.

[2] Plöthner M, Frank M, von der Schulenburg JG. Cost analysis of whole genome sequencing in German clinical practice. Eur J Health Econ 2017;18:623-33.

[3] van Nimwegen KJ, van Soest RA, Veltman JA, Nelen MR, van der Wilt GJ, Vissers LE, et al. Is the $\$ 1000$ genome as near as we think? A cost analysis of next-generation sequencing. Clin Chem 2016 Nov;62(11):1458-64.

[4] Hamburg MA, Collins FS. The path to personalized medicine. N Engl J Med 2010;363:3014.

[5] Truntzer C, Maucort-Boulch D, Roy P. Comparative optimism in models involving both classical clinical and gene expression information. BMC Bioinformatics 2008;9:434.

[6] Ioannidis JP. Why most published research findings are false. PLoS Med 2005;2:e124.

[7] Lee SM, Falzon M, Blackhall F, Spicer J, Nicolson M, Chaudhuri A, et al. Randomized prospective biomarker trial of ERCC1 for comparing platinum and nonplatinum therapy in advanced non-small-cell lung cancer: ERCC1 Trial (ET). J Clin Oncol 2017;35:402-11.

[8] de Leon J. Evidence-based medicine versus personalized medicine: are they enemies? J Clin Psychopharmacol 2012;32:153-64.

[9] Kalia SS, Adelman K, Bale SJ, Chung WK, Eng C, Evans JP, et al. Recommendations for reporting of secondary findings in clinical exome and genome sequencing, 2016 update (ACMG SF v2.0): a policy statement of the American College of Medical Genetics and Genomics. Genet Med 2017;19:249-55.

[10] Inouye M, Abraham G, Nelson CP, Wood AM, Sweeting MJ, Dudbridge F, et al. Genomic risk prediction of coronary artery disease in 480,000 adults: Implications for primary prevention. J Am Coll Cardiol 2018;72:1883-93.

[11] Picard N, Boyer JC, Etienne-Grimaldi MC, Barin-Le Guellec C, Thomas F, Loriot MA, Réseau national de pharmacogénétique (RNPGx), Traitements personnalisés grâce à la pharmacogénétique : niveaux de preuve et de recommandations du Réseau national de pharmacogénétique (RNPGx). Therapie 2017;72:175-83. doi: 10.1016/j.therap.2016.09.007.

[12] van der Wouden CH, Cambon-Thomsen A, Cecchin E, Cheung KC, Dávila-Fajardo CL, Deneer VH, et al. Implementing pharmacogenomics in Europe: design and implementation strategy of the Ubiquitous Pharmacogenomics Consortium. Clin Pharmacol Ther 2017;101:341-58. 
[13] Haute autorité de santé (HAS). Test compagnon associé à une thérapie ciblée : définitions et méthode d'évaluation. Février 2014. https://www.hassante.fr/portail/upload/docs/application/pdf/2014-04/guide_meth_court_test_cpagnon_vd.pdf. [Accessed 11 December 2018 (27 pp.)].

[14] Gueyffier F, Piedbois P, Bergmann JF, Avouac B, Borel T, Boussageon R, et al. Comment mesure-t-on le bénéfice net d'un traitement? Therapie 2017;72:39-49, 51-61.

[15] Chatellier G, Varlet V, Blachier-Poisson C, Beslay N, Behier JM, Braunstein D, et al. "Big data" and "open data": What kind of access should researchers enjoy? Therapie 2016 Feb;71(1):97-105, 107-14. doi: 10.1016/j.therap.2016.01.005.

[16] Comité consultatif national d'éthique. Avis 129. Contribution du Comité consultatif national d'éthique à la révision de la loi de bioéthique. 2018. https://www.ccneethique.fr/sites/default/files/avis_129_vf.pdf._Accessed 11 December 2018 (165 pp.)]

[17] Marino P, Touzani R, Perrier L, Rouleau E, Kossi DS, Zhaomin Z, et al. Cost of cancer diagnosis using next-generation sequencing targeted gene panels in routine practice: a nationwide French study. Eur J Hum Genet 2018;26:314-23.

[18] Schwarze K, Buchanan J, Taylor JC, Wordsworth S. Are whole-exome and whole-genome sequencing approaches cost-effective? A systematic review of the literature. Genet Med 2018;20:1122-30.

[19] Bennette CS, Gallego CJ, Burke W, Jarvik GP, Veenstra DL. The cost-effectiveness of returning incidental findings from next-generation genomic sequencing. Genet Med 2015;17:587-95.

[20] Payne K, Gavan SP, Wright SJ, Thompson AJ. Cost-effectiveness analyses of genetic and genomic diagnostic tests. Nat Rev Genet 2018;19:235-46.

[21] Rejeb O, Pilet C, Hamana S, Xie X, Durand T, Aloui S, et al. Performance and cost evaluation of health information systems using micro-costing and discrete-event simulation. Health Care Manag Sci 2018;21:204-23.

[22] Haute autorité de santé. Guide méthodologique. Choix méthodologique pour l'évaluation économique à la HAS. Octobre 2011. https://www.hassante.fr/portail/upload/docs/application/pdf/2011-11/guide_methodo_vf.pdf. [Accessed 11 December 2018 (83 pp.)].

[23] Tuppin P, Rudant J, Constantinou P, Gastaldi-Ménager C, Rachas A, de Roquefeuil L, et al. Value of a national administrative database to guide public decisions: From the système national d'information interrégimes de l'Assurance Maladie (SNIIRAM) to the système national 
des données de santé (SNDS) in France. Rev Epidemiol Sante Publique 2017;65 Suppl 4:S149S167.

S167. 